BRAVILLIAN JOURNAL

www.bjournal.com.br
ISSN 0100-879X

Volume 43 (3) 182-267 March 2011

BIOMEDICAL SCIENCES

AND

CLINICAL INVESTIGATION

Braz J Med Biol Res, March 2011, Volume 44(3) 200-205

doi: 10.1590/S0100-879X2011007500019

CCN2/CTGF silencing blocks cell aggregation in embryonal carcinoma P19 cell

D.P. Aguiar, J.M. Coelho-Aguiar and J.G. Abreu

The Brazilian Journal of Medical and Biological Research is partially financed by

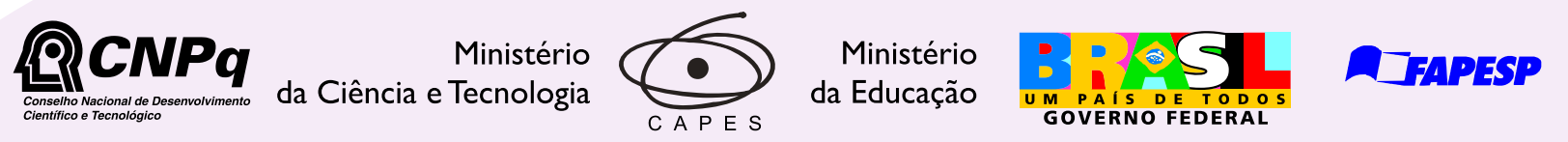

Institutional Sponsors
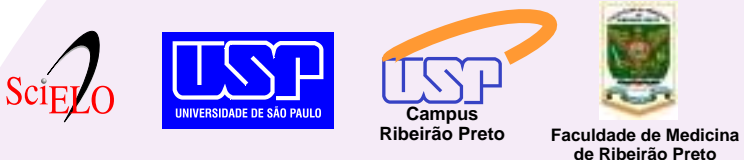

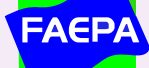

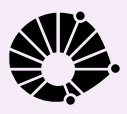

$\oplus$ SHIMADZU

GE Healthcare
Hotsite of proteomics metabolomics developped by:

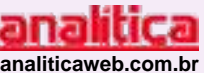




\title{
CCN2/CTGF silencing blocks cell aggregation in embryonal carcinoma P19 cell
}

\author{
D.P. Aguiar, J.M. Coelho-Aguiar and J.G. Abreu
}

Programa de Biologia Celular e do Desenvolvimento, Instituto de Ciências Biomédicas, Universidade Federal do Rio de Janeiro, Rio de Janeiro, RJ, Brasil

\begin{abstract}
Connective tissue growth factor (CCN2/CTGF) is a matricellular-secreted protein involved in extracellular matrix remodeling. The P19 cell line is an embryonic carcinoma line widely used as a cellular model for differentiation and migration studies. In the present study, we employed an exogenous source of CCN2 and small interference RNA to address the role of CCN2 in the P19 cell aggregation phenomenon. Our data showed that increasing CCN2 protein concentrations from 0.1 to $20 \mathrm{nM}$ decreased the number of cell clusters and dramatically increased cluster size without changing proliferation or cell survival, suggesting that CCN2 induced aggregation. In addition, CCN2 specific silencing inhibited typical P19 cell aggregation, which could be partially rescued by $20 \mathrm{nM}$ CCN2. The present study demonstrates that CCN2 is a key molecule for cell aggregation of embryonic P19 cells.
\end{abstract}

Key words: Teratocarcinoma; Adhesion; Condensation; CCN family; CCN2/CTGF; Extracellular matrix

\section{Introduction}

Connective tissue growth factor (CCN2/CTGF) is a member of the CCN [CYR61 (cysteine-rich 61)/CTGF NOV (nephroblastoma over-expressed)] family of matricellular signaling modulators. These modulators are characterized by four conserved modules that share homology with different protein domains $(1,2)$. The amino terminus of the first module displays homology with an insulin-like growth factor binding protein. The second module is a von Willebrand factor type C/Chordin-like cysteine-rich domain (2). After a cysteine-free sequence, the third module displays homology to the thrombospondin type 1 repeat and contains a cysteine-knot at the carboxy-terminus. During development, CCN2 expression is mostly detected in tissues of compact cell organization, such as notochord, somites, cartilage $(3,4)$, and Merckel's cartilage (5), and also in mesenchymal condensation (6). Although several studies have indicated that $\mathrm{CCN} 2$ is a pleiotropic molecule, there are compelling data showing that CCN2 can function in the maintenance of multicellular spheroid aggregates as in ovarian cancer cells (7) and in mesenchymal cell condensation during chondrocyte differentiation (6). P19 mouse embryonic carcinoma cells have been used extensively as a model to address questions related to cell aggregation and differentiation (8,9). P19 cells have tumor stem cell features and resemble embryonic multipotent cell since they are able to give rise to different cell types derived from the three germ layers (10). P19 cells are a suitable model for the study of cell differentiation, which is an essential cellular process for embryonic development and tissue formation. In monolayer culture, P19 cells treated with retinoic acid can differentiate into neural-like cells (11). In the presence of dimethyl sulfoxide (DMSO), P19 cell clusters rapidly differentiate to form large amounts of cardiac and skeletal muscle but they never give rise to neurons or glial cells $(3,11)$. Cell attachment is a crucial step in tissue regeneration and the increase in CCN2 expression has been correlated with cell attachment (12). Cell aggregation is a prerequisite for the in vitro and in vivo (13) differentiation of mesenchymal stem cells from adult somatic tissues into multiple mesodermderived cell types including bone, cartilage, adipose tissue, tendon, ligament, or even muscle $(14,15)$. The CCN2 molecule is implicated in these events, cooperating with other substances such as integrin alpha5beta3 (16), TGF-beta1 (3), aggrecan (17), focal adhesion kinase, and promoting the activation of transcription factors such as ERK $1 / 2$ and NF-kappa B (6). Recent studies have shown that CCN2 mediates drug resistance in human breast cancer by increasing cell viability through the activation of the survival

Correspondence: J.G. Abreu, Programa de Biologia Celular e do Desenvolvimento, Instituto de Ciências Biomédicas, UFRJ, Bloco F, Sala 9, 21949-590 Rio de Janeiro, RJ, Brasil. E-mail: garciajr@anato.ufrj.br

Received August 30, 2010. Accepted January 3, 2011. Available online February 18, 2011. Published March 7, 2011. 
pathway by up-regulation of ERK1/2-dependent Bcl-xL/ clAP1 (18). This type of cancer remains aggregated and contains a high percentage of stem cells (19). Although cell aggregation has been studied for decades, its implication in both embryonic development and progress of particular diseases is not fully understood. In the present study, we investigated the cell aggregation properties of embryonic carcinoma P19 cells in culture under the influence of CCN2 protein. Our data show that CCN2 is sufficient for P19 cell aggregation and strongly suggest that CCN2 is a chemoattractant molecule for these stem-like cells.

\section{Material and Methods}

\section{Cell culture}

P19 embryonic carcinoma cells were purchased from the American Type Culture Collection (ATCC, USA). Cells were cultured in a-MEM (Sigma-Aldrich, WGK, Germany) supplemented with $10 \%$ fetal bovine serum (FBS) (Invitrogen/Gibco, New Zealand) and split every 2 days. After the first $24 \mathrm{~h}$ P19 were incubated for more than $24 \mathrm{~h}$ with CCN2 at $37^{\circ} \mathrm{C}$ in $5 \% \mathrm{CO}_{2}$.

Flag epitope-tagged construct of full-length CCN2 protein was prepared using S2 stable cells (3), which were cultured in Schneider's Drosophila Medium supplemented with $10 \%$ FBS (Invitrogen/Gibco) and $56 \mu \mathrm{M}$ hygromycin-B (Sigma, USA). Cells were split every 4 days and kept at $22^{\circ} \mathrm{C}$. Full-length CCN2-Flag protein was purified as previously described (3). Protein concentration was determined by the method of Lowry et al. (20).

\section{siRNA synthesis and utilization}

To silence CCN2 expression in P19 cells, we performed small interference RNA (siRNA). Two siRNAs were synthesized using the Ambion Silencer siRNA construction kit as a reference guide (Ambion, USA). The oligonucleotides used to target the CCN2-RNA (accession No. NM_010217) sequences were (CCN2-siRNA1) GAAGACUCAGCCAG AUCCAUU sense, UGGAUCUGGCUGAGUCUUCUU antisense (CCN2-siRNA2), AGCAGCUGCAAAUACCAAUUU sense, AUUGGUAUUUGCAGCUGCUUU antisense. The CCN2-siRNA1 and CCN2-siRNA2 (negative control) were transfected using RNAiFect (Qiagen, USA, 301,605) in P19 cells at $50-70 \%$ confluence. The transfection procedures were carried out by the method of Rober et al. (21). To perform rescuing experiments, $20 \mathrm{nM}$ recombinant CCN2 was added in $1 \%$ FBS culture medium after $24 \mathrm{~h}$ of siRNA silencing. Since only CCN2 siRNA1 was able to block CCN2 translation (data not shown) we used CCN2-siRNA2 as a negative control to check possible cytotoxic or nonspecific effects caused by CCN2-siRNA1.

\section{Cell proliferation and $\left[{ }^{3} \mathrm{H}\right]$-thymidine incorporation assays \\ P19 cells were seeded at $1 \times 10^{5}$ cells per well in $\alpha-M E M$}

with $1 \%$ FBS in 24-well dishes, treated or not with various concentration of CCN2 $(0.1,5$, and $20 \mathrm{nM})$ depending on the experimental series. $A\left[{ }^{3} \mathrm{H}\right]$-thymidine pulse was added to the cell culture along with the CCN2. After $24 \mathrm{~h}$, the medium was removed, the cultures were washed three times with PBS and $300 \mu \mathrm{L}$ ice-cold $10 \%$ trichloroacetic acid was added to each well. The cells were harvested and $\left[{ }^{3} \mathrm{H}\right]$-thymidine incorporation was measured with a scintillation counter. Each experiment was performed at least three times using three culture wells per condition.

\section{Cell viability assay}

Cell viability and growth were measured by the MTT assay $(22,23)$. The yellow tetrazolium salt (3-(4,5-dimethylthiazol2-yl)-2,5-diphenyltetrazolium bromide; MTT) was reduced in metabolically active cells to form insoluble purple formazan crystals, which were solubilized by the addition of DMSO and then quantified by spectrophotometry at $340 \mathrm{~nm}$.

\section{Western blot}

CCN2 expression levels were monitored by Western blot analysis. Treated and untreated cell cultures were washed three times with $1 \mathrm{X}$ PBS, and then harvested in sample buffer [20 $\mu \mathrm{M}$ dithioreitol (DTT); $1.38 \mathrm{mM}$ sodium dodecyl sulfate (SDS); $125 \mathrm{mM}$ Tris- $\mathrm{HCl}, \mathrm{pH} 6.8$, and $20 \%$ glycerol]. The samples were submitted to $12 \%$ SDS-polyacrylamide gel electrophoresis (SDS-PAGE), electroblotted and transferred to a PVDF membrane (HybondTM-P, Amersham Biosciences, Brazil). Membranes were pre-incubated in 5\% non-fat dry milk in Tris-buffered saline containing $0.001 \%$ Tween 20 (TBS-T) for $1 \mathrm{~h}$ and then incubated with the primary polyclonal antibody anti-CTGF (Torrey Pines Biolabs, USA, 1:1000) and anti-tubulin (Sigma, 1:2000) overnight. The reaction was visualized using the SuperSignal West Pico Chemiluminescent Substrate (Pierce, USA).

\section{Quantification parameters}

To measure the cluster size, aggregates submitted to specific treatments were photographed and the area of each aggregate was quantified with the Image J software (NIH-Image - http://rsbweb.nih.gov/ij). The ImageJ software quantifies the number of pixels in the cluster area that is defined by a line around the cluster perimeter. The values attributed to these pixels were defined as arbitrary units. For each condition, 20 fields were randomly chosen and 500 clusters were counted. Only clusters consisting of more than 10 cells were counted. The values obtained for different experimental conditions were analyzed with the GraphPad Prism 4.0 software (www. graphpad.com). Statistical analysis was performed using the non-parametric Mann-Whitney test (24).

\section{Results}

\section{CCN2 increases $\mathrm{P} 19$ cell cluster size}

The presence of $\mathrm{CCN} 2$ protein has been related to 
mesenchymal condensation during embryonic development $(4,6,25)$, a phenomenon that involves aggregation and chemoattraction. However, these morphological changes have not yet been fully investigated in stem-like cells. To gain insight into the aggregation properties of CCN2 protein, $\mathrm{P} 19$ cells were treated for $24 \mathrm{~h}$ with different concentrations of recombinant CCN2 (Figure 1). Even at low confluence, P19 cells tend to form some epithelial-like aggregates in culture (11) (Figure 1A). But the addition of $20 \mathrm{nM}$ CCN2 recombinant protein induced larger aggregates (Figure 1B). The effect of CCN2 on morphological aggregation clusters was analyzed in terms of number and size. Only clusters containing more than 10 cells were scored. We detected an average of 30 small clusters of $\mathrm{P} 19$ cells not treated with CCN2 (Figure 1C). There was a dose-response reduction of clusters with CCN2 concentration, and $20 \mathrm{nM} \mathrm{CCN} 2$ reduced the number of $\mathrm{P} 19$ clusters to roughly $50 \%$ compared to untreated cells (Figure 1C). There was a dose-dependent increase in cluster size with CCN2 (Figure 1D).

These observations suggested that CCN2 protein promoted cell aggregation or induced cell proliferation or both. $\left[{ }^{3} \mathrm{H}\right]$-thymidine incorporation experiments were performed with P19 cells cultured with or without CCN2 for $24 \mathrm{~h}$. No significant difference in proliferation rate was detected between untreated and CCN2-treated P19 cells, showing that the increase in cluster size was not due to cell proliferation (data not shown).

Since CCN2-treated P19 cells have larger but fewer clusters than untreated cells, we determined if CCN2 could regulate cell viability. The determination of cell viability with MTT did not show significant differences between untreated $\mathrm{P} 19$ cells and cells treated with $0.1,0.5$ or $20 \mathrm{nM} \mathrm{CCN2}$ (data not shown). Therefore, the increase in P19 cell cluster size was probably induced by aggregation.

\section{CCN2 silencing impairs P19 cell aggregation}

To examine the requirement of CCN2 for P19 cell aggregation, CCN2-siRNA silencing (CCN2-siRNA) was performed. We silenced CCN2 for $24 \mathrm{~h}$ by transfecting CCN2-siRNA1. CCN2 protein silencing in P19 cells was detected by Western blotting of the cell extracts using an anti-CCN2 antibody (Figure 2A). The endogenous CCN2 protein was silenced by CCN2-siRNA1 (Figure 2A, lane 3). P19 cells transfected with CCN2-siRNA2, whose oligonucleotide sequences were not able to block CCN2 protein translation (data not shown), display morphology and aggregation pattern similar to those of untreated $\mathrm{P} 19$ cells (Table 1, see Methods for details). The addi- tion of $20 \mathrm{nM}$ CCN2 recombinant protein allowed us to detect CCN2 (Figure 2A, lane 4). CCN2-siRNA1-transfected and -untransfected $\mathrm{P} 19$ cells were analyzed in terms of cluster formation (Figure 2B, C and E). CCN2-siRNA1-transfected P19 cells present clusters that were smaller compared to untransfected and CCN2-siRNA2-transfected cells (negative control, data not shown). In addition cells appeared to be dissociated in CCN2-siRNA1-transfected cultures (Figure $2 \mathrm{E})$. Interestingly, the addition of $20 \mathrm{nM}$ recombinant CCN2 protein to CCN2-siRNA1-transfected P19 cells was able to achieve the normal cluster size observed in untreated cells, but did not reach the phenotype observed in $20 \mathrm{nM}$ CCN2-treated cells (Figure 2C, D and F). The cluster size of CCN2-siRNA1 P19 cells treated with 20 nM CCN2 indicated that the cells had retained their natural state of aggregation since the cluster sizes were similar to those found in untreated P19 cells (Figure 2B).

We quantified the percentage of cells in the clusters during the aggregating phenomenon promoted by CCN2. Four categories of clusters were established based on the number of cells per cluster (Table 1). In untreated cultures, almost $60 \%$ of the clusters are formed by 25 to 50 cells per cluster (Table 1). Conversely, in cultures treated with 0.1 and $5 \mathrm{nM}$ CCN2, the percentage of cells per cluster increases and in cultures treated with $20 \mathrm{nM}$ CCN2 approximately $70 \%$ of the clusters consist of $>75$ cells per cluster (Table 1 ). In CCN2siRNA1-transfected cultures, only clusters containing less
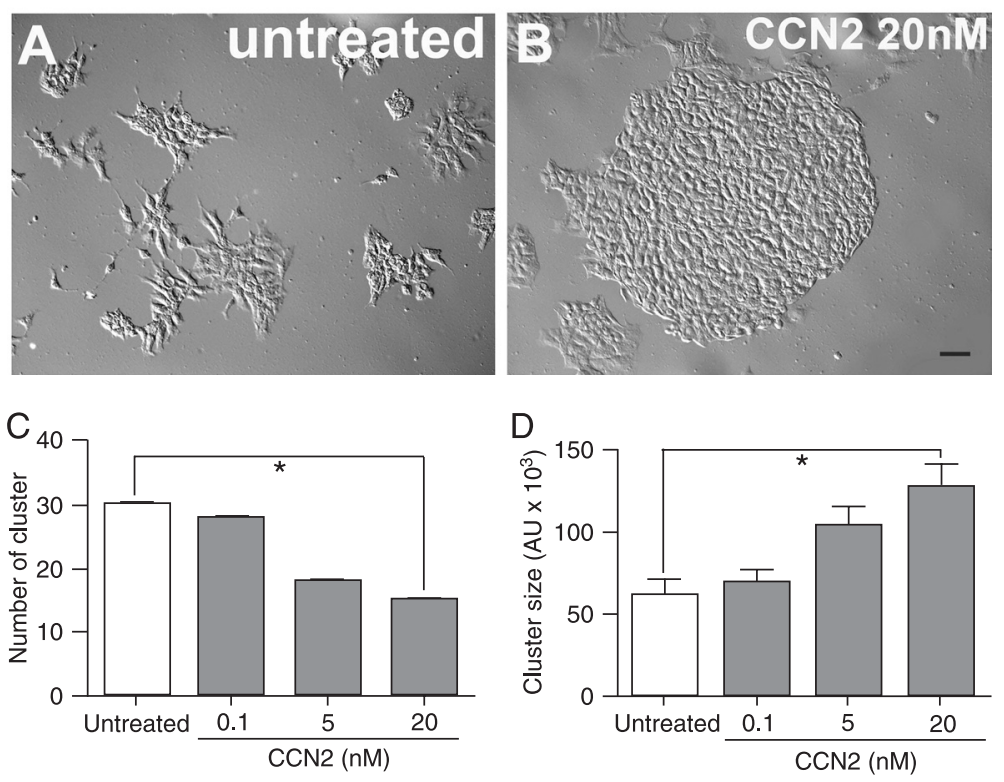

Figure 1. CCN2 induces P19 cell aggregation. Phase contrast microscopy of P19 cells grown for $24 \mathrm{~h}$ under control culture conditions (A), or in the presence of $20 \mathrm{nM}$ recombinant CCN2 (B). Graph bars showing the quantitation of P19 cluster number (C) and the cluster area (D) of untreated cells and of cells treated with $0.1,5$, and $20 \mathrm{nM} \mathrm{CCN2}$. Each experiment was carried out in triplicate. $\mathrm{N}=$ 4 , scale bar $50 \mu \mathrm{m}$. AU = arbitrary units. ${ }^{*} P<0.05$ as indicated (non-parametric Mann-Whitney test). 
A
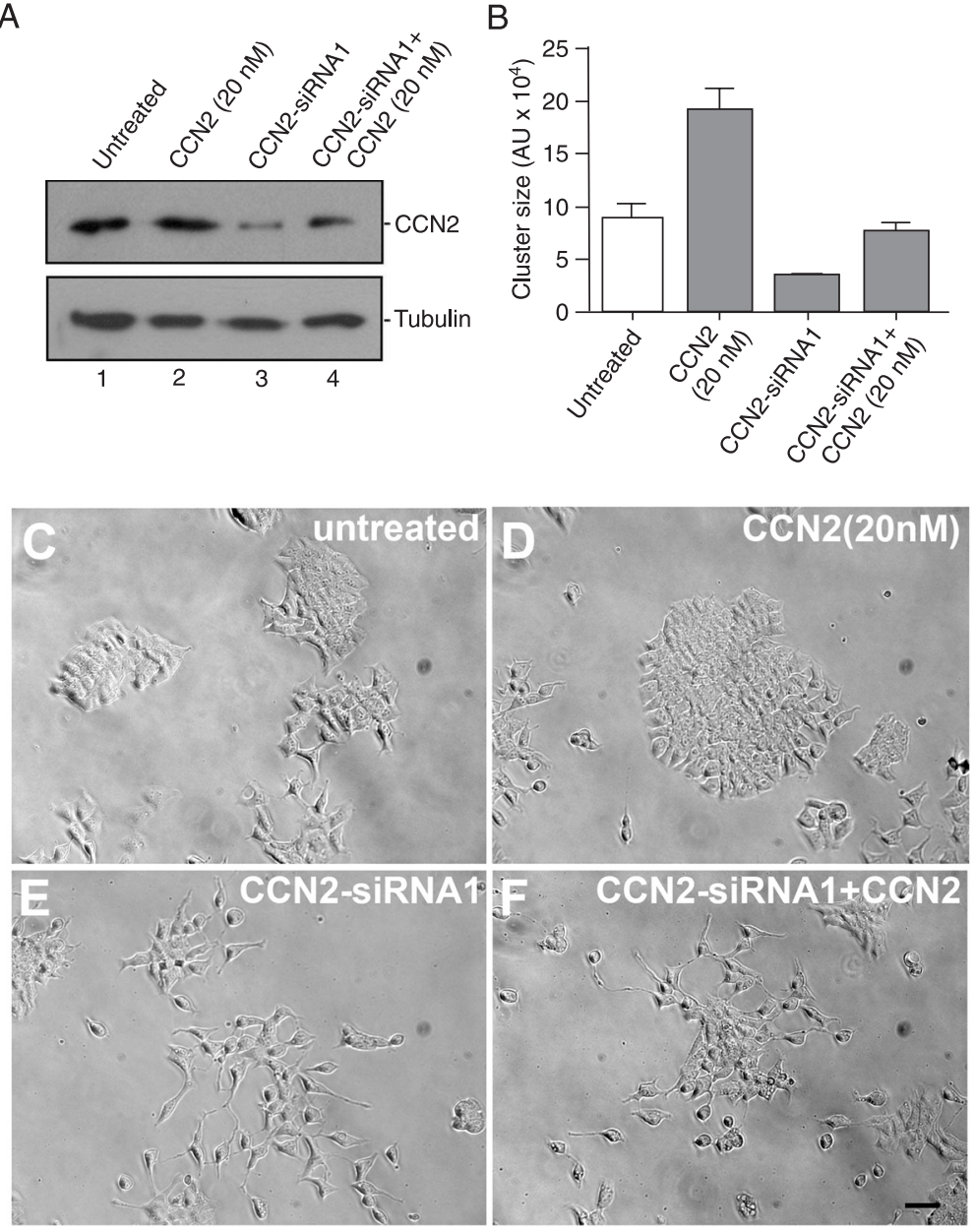

Figure 2. $\mathrm{CCN} 2$ is required for $\mathrm{P} 19$ cell aggregation. $A$, Immunoblotting detection of CCN2 protein in P19 extracts of untreated cells (lane 1) and of cells treated with $20 \mathrm{nM}$ CCN2 (lane 2), CCN2-siRNA1 (lane 3), and CCN2-siRNA1 plus $20 \mathrm{nM}$ CCN2 (lane 4). Tubulin detection was used as a loading control. $B$, Cluster size of P19 cells and of cells treated with 20 nM CCN2, CCN2-siRNA1, and CCN2-siRNA1 plus $20 \mathrm{nM}$ CCN2 protein. Phase contrast microscopy of untreated P19 cells (C), in the presence of $20 \mathrm{nM}$ recombinant CCN2 (D), transfected with CCN2-siRNA1 (E) and with CCN2-siRNA1 plus $20 \mathrm{nM}$ CCN2 protein (F). Each experiment was carried out in triplicate. $N=4$; scale bar $50 \mu \mathrm{m}$ for all panels. than 25 cells were observed. The addition of CCN2 protein partially reversed the inhibition of cluster formation by CCN2-siRNA1 and no effect was observed on cluster formation in CCN2-siRNA2 (scramble siRNA)-treated cells (Table 1). Since proliferation was not modified by CCN2, these results strongly suggest that CCN2 induces P19 cell aggregation.

\section{Discussion}

The present study addressed the aggregation induced by CCN2/CTGF of embryonic carcinoma P19 cells in culture. Our data show that CCN2/CTGF induces cluster formation when added exogenously to P19 culture media. Conversely, silencing of CCN2/CTGF protein by siRNA inhibits P19 cluster formation (Table 1). Therefore, our data indicate CCN2/CTGF as a pivotal component of the P19 cell aggregation machinery.

Several reports have documented CCN2-mediated adhesion in adult mesenchyme-derived cells such as fibroblasts, osteoblasts, chondrocytes, myoblasts, stellate and mesangial cells $(9,26-30)$. However, the role of CCN2 in the aggregation of embryonic carcinoma cells has not been investigated. P19 cells have the potential to differentiate into ectoderm or mesoderm cell lineages by adopting embryonic body-like structures or monolayer morphology, respectively, depending on the treatment (11,31-33). These features suggest that the aggregation of these cells is an important step during the establishment of their differentiation program. Thus, these cells provide an excellent tool to understand the events controlling cell aggregation, proliferation and differentiation. We have shown that monolayers of P19

Table 1. Cell cluster analysis showing different percentages of cells per cluster in each experimental condition.

\begin{tabular}{|c|c|c|c|c|c|c|c|}
\hline \multirow{2}{*}{$\begin{array}{l}\text { Number of cells } \\
\text { per cluster }\end{array}$} & \multirow[t]{2}{*}{ Untreated } & \multicolumn{3}{|c|}{$\mathrm{CCN} 2$} & \multirow[t]{2}{*}{ CCN2-siRNA1 } & \multirow[t]{2}{*}{ CCN2-siRNA1 + CCN2 (20 nM) } & \multirow[t]{2}{*}{ CCN2-siRNA2 } \\
\hline & & $0.1 \mathrm{nM}$ & $5 \mathrm{nM}$ & $20 \mathrm{nM}$ & & & \\
\hline$<25$ & $22.4 \%$ & $9.5 \%$ & $3.3 \%$ & $4.3 \%$ & $100 \%$ & $65.2 \%$ & $36.0 \%$ \\
\hline $25-50$ & $58.6 \%$ & $4.5 \%$ & $10.0 \%$ & $4.3 \%$ & 0 & $34.8 \%$ & $47.6 \%$ \\
\hline $51-75$ & $15.5 \%$ & $26.2 \%$ & $26.6 \%$ & $17.4 \%$ & 0 & 0 & $14.3 \%$ \\
\hline$>75$ & $3.5 \%$ & $19.1 \%$ & $60.0 \%$ & $73.9 \%$ & 0 & 0 & $2.1 \%$ \\
\hline
\end{tabular}


and Mv1Lu cells form spherical aggregates when CCN2 and TGFß-1 are added together to the culture medium (3). Under these conditions, the spherical aggregates were able to express endothelial markers and to adopt an aggregate morphology during their differentiation. The CCN2 protein is highly expressed during early development in morphogenetic areas where migratory behavior, adhesion properties and pluripotency state are cellular characteristics for tissue organization, as shown in Xenopus leavis and in mice $(3,4,34)$. Furthermore, cell adhesion is also critical for tumor survival and progression. In addition, some tumor cells can adopt an embryonic behavior and express pluripotency markers, including octamer-binding transcription factor 4 and Nanog (35). Thus, acquisition of adhesion potential could explain why CCN2 has been implicated in metastasis $(36,37)$. Our findings have brought more information regarding chemoadhesive and aggregation behavior upon CCN2 stimulation; therefore, P19 cells combine properties of cell pluripotency as well as tumor behavior.

Cell condensation results from different interactions between cell surface receptors and molecules of the microenvironment such as extracellular matrix-related proteins and glycoproteins. In fact, it has been reported that CCN2 interacts with fibronectin $(25,38)$ and that, during migration, cells can perform attachment/detachment and undergo cytoskeletal actin rearrangement to move upon the extracellular matrix network $(9,11)$. In our analysis of the cluster number and size of untreated versus CCN2-treated cells, we noticed an inverse correlation, i.e., the larger the cluster, the lower the number of clusters, suggesting that cells reorganize the culture topology probably by migrating and aggregating toward colony formation. One could argue that small colonies of untreated P19 cells could proliferate in response to CCN2. However, this does not seem to be the case since the $\left[{ }^{3} \mathrm{H}\right]$-thymidine incorporation assay did not reveal differences in proliferation between CCN2-treated

\section{References}

1. Bork P. The modular architecture of a new family of growth regulators related to connective tissue growth factor. FEBS Lett 1993; 327: 125-130.

2. Garcia Abreu J, Coffinier C, Larrain J, Oelgeschlager M, De Robertis EM. Chordin-like CR domains and the regulation of evolutionarily conserved extracellular signaling systems. Gene 2002; 287: 39-47.

3. Abreu JG, Ketpura NI, Reversade B, De Robertis EM. Connective-tissue growth factor (CTGF) modulates cell signalling by BMP and TGF-beta. Nat Cell Biol 2002; 4: 599604.

4. Ivkovic S, Yoon BS, Popoff SN, Safadi FF, Libuda DE, Stephenson RC, et al. Connective tissue growth factor coordinates chondrogenesis and angiogenesis during skeletal development. Development 2003; 130: 2779-2791.

5. Shimo T, Kanyama M, Wu C, Sugito H, Billings PC, Abrams and -untreated P19 cells. Since CCN2 addition did not affect cell proliferation, the increase in size followed by a decrease in cluster number could be interpreted as cells migrating from clusters to form larger clusters by aggregation. Alternatively and less likely, CCN2 addition could also favor cluster aggregation, which indeed, in any way would decrease the number of clusters. Indeed, this result is consistent with previous findings showing that $\mathrm{CCN} 2$ induces cell migration and cytoskeleton actin rearrangement in human mesangial cells $(9,11)$. Silencing of CCN2 by siRNA on P19 cells had a noticeable effect on the inhibition of cluster formation. Interestingly, the addition of CCN2 recombinant protein to CCN2-siRNA1 P19 cells did not induce a large cluster, but restored the basal capacity of P19 cell to form aggregates. A possible explanation for this would be that the exogenous source of CCN2 induced cell reaggregation to the normal phenotype in culture. Further experiments are needed to determine whether CCN2 can modulate the expression of other CCN members such as CCN1 that could mediate cell aggregation in $\mathrm{P} 19$ cells (39).

The current study addressed the chemoadhesive and aggregant properties of CCN2 also for embryonic carcinoma P19 cells, showing that CCN2 induces cell aggregation and that this phenomenon occurs in a CCN2 dose-dependent manner. Since P19 cells have been used extensively as a model/tool in stem cell differentiation research (40), our data may contribute to a better understanding of P19 adhesion properties, which are crucial in most of the approaches employed in such studies.

\section{Acknowledgments}

We thank Dr. Sophie Creuzet and Dr. Vivaldo Moura Neto for their comments about the manuscript. Research supported by CNPq, CAPES, PRONEX, and FAPERJ.
WR, et al. Expression and roles of connective tissue growth factor in Meckel's cartilage development. Dev Dyn 2004; 231: 136-147.

6. Song JJ, Aswad R, Kanaan RA, Rico MC, Owen TA, Barbe $\mathrm{MF}$, et al. Connective tissue growth factor (CTGF) acts as a downstream mediator of TGF-beta1 to induce mesenchymal cell condensation. J Cell Physiol 2007; 210: 398-410.

7. Sodek KL, Ringuette MJ, Brown TJ. Compact spheroid formation by ovarian cancer cells is associated with contractile behavior and an invasive phenotype. Int J Cancer 2009; 124: 2060-2070.

8. Soprano DR, Teets BW, Soprano KJ. Role of retinoic acid in the differentiation of embryonal carcinoma and embryonic stem cells. Vitam Horm 2007; 75: 69-95.

9. Gao X, Tian HY, Liu L, Yu ML, Jing NH, Zhao FK. Comparative proteomic analysis of proteins involved in cell aggrega- 
tion during neural differentiation of P19 mouse embryonic carcinoma cells. J Proteome Res 2009; 8: 1765-1781.

10. Rossant J, Papaioannou VE. Outgrowth of embryonal carcinoma cells from injected blastocysts in vitro correlates with abnormal chimera development in vivo. Exp Cell Res 1985; 156: 213-220.

11. McBurney MW, Jones-Villeneuve EM, Edwards MK, Anderson PJ. Control of muscle and neuronal differentiation in a cultured embryonal carcinoma cell line. Nature 1982; 299: 165-167.

12. Leask A, Abraham DJ. The role of connective tissue growth factor, a multifunctional matricellular protein, in fibroblast biology. Biochem Cell Biol 2003; 81: 355-363.

13. Steinberg MS. Differential adhesion in morphogenesis: a modern view. Curr Opin Genet Dev 2007; 17: 281-286.

14. Nishida T, Maeda A, Kubota S, Takigawa M. Role of mechanical-stress inducible protein Hcs24/CTGF/CCN2 in cartilage growth and regeneration: mechanical stress induces expression of Hcs24/CTGF/CCN2 in a human chondrocytic cell line HCS-2/8, rabbit costal chondrocytes and meniscus tissue cells. Biorheology 2008; 45: 289-299.

15. Ono M, Kubota S, Fujisawa T, Sonoyama W, Kawaki H, Akiyama K, et al. Promotion of hydroxyapatite-associated, stem cell-based bone regeneration by CCN2. Cell Transplant 2008; 17: 231-240.

16. Tan TW, Lai CH, Huang CY, Yang WH, Chen HT, Hsu HC, et al. CTGF enhances migration and MMP-13 up-regulation via alphavbeta3 integrin, FAK, ERK, and NF-kappaB-dependent pathway in human chondrosarcoma cells. J Cell Biochem 2009; 107: 345-356.

17. Aoyama E, Hattori T, Hoshijima M, Araki D, Nishida T, Kubota $\mathrm{S}$, et al. N-terminal domains of CCN family $2 /$ connective tissue growth factor bind to aggrecan. Biochem J 2009; 420: 413-420.

18. Wang MY, Chen PS, Prakash E, Hsu HC, Huang HY, Lin MT, et al. Connective tissue growth factor confers drug resistance in breast cancer through concomitant up-regulation of Bcl-xL and clAP1. Cancer Res 2009; 69: 3482-3491.

19. Korkaya H, Paulson A, Charafe-Jauffret E, Ginestier C, Brown M, Dutcher J, et al. Regulation of mammary stem/ progenitor cells by PTEN/Akt/beta-catenin signaling. PLoS Biol 2009; 7: e1000121.

20. Lowry OH, Rosebrough NJ, Farr AL, Randall RJ. Protein measurement with the Folin phenol reagent. $J$ Biol Chem 1951; 193: 265-275.

21. Rober RA, Sauter H, Weber K, Osborn M. Cells of the cellular immune and hemopoietic system of the mouse lack lamins A/C: distinction versus other somatic cells. J Cell Sci 1990; 95 (Part 4): 587-598.

22. Amado NG, Cerqueira DM, Menezes FS, da Silva JF, Neto VM, Abreu JG. Isoquercitrin isolated from Hyptis fasciculata reduces glioblastoma cell proliferation and changes betacatenin cellular localization. Anticancer Drugs 2009; 20: 543-552.

23. Vistica DT, Skehan P, Scudiero D, Monks A, Pittman A, Boyd MR. Tetrazolium-based assays for cellular viability: a critical examination of selected parameters affecting formazan production. Cancer Res 1991; 51: 2515-2520.

24. Siegel S. Non-parametric statistics for behavioral sciences. New York: McGraw Hill; 1956.

25. Chen XM, Qi W, Pollock CA. CTGF and chronic kidney fibrosis. Front Biosci 2009; 1: 132-141.
26. Babic AM, Chen CC, Lau LF. Fisp12/mouse connective tissue growth factor mediates endothelial cell adhesion and migration through integrin alphavbeta3, promotes endothelial cell survival, and induces angiogenesis in vivo. Mol Cell Biol 1999; 19: 2958-2966.

27. Brigstock DR. Strategies for blocking the fibrogenic actions of connective tissue growth factor (CCN2): From pharmacological inhibition in vitro to targeted siRNA therapy in vivo. $J$ Cell Commun Signal 2009; 3: 5-18.

28. Perbal B. Ten years later. J Cell Commun Signal 2009; 3: 1-3.

29. Schutze N, Noth U, Schneidereit J, Hendrich C, Jakob F. Differential expression of CCN-family members in primary human bone marrow-derived mesenchymal stem cells during osteogenic, chondrogenic and adipogenic differentiation. Cell Commun Signal 2005; 3: 5.

30. Maeda A, Nishida T, Aoyama E, Kubota S, Lyons KM, Kuboki T, et al. CCN family $2 /$ connective tissue growth factor modulates BMP signalling as a signal conductor, which action regulates the proliferation and differentiation of chondrocytes. J Biochem 2009; 145: 207-216.

31. Okamoto K, Okazawa H, Okuda A, Sakai M, Muramatsu M, Hamada $\mathrm{H}$. A novel octamer binding transcription factor is differentially expressed in mouse embryonic cells. Cell 1990; 60: 461-472.

32. Suzuki T, Kim HS, Kurabayashi M, Hamada H, Fujii H, Aikawa M, et al. Preferential differentiation of P19 mouse embryonal carcinoma cells into smooth muscle cells. Use of retinoic acid and antisense against the central nervous system-specific POU transcription factor Brn-2. Circ Res 1996; 78: 395-404.

33. Santiago MF, Liour SS, Mendez-Otero R, Yu RK. Glialguided neuronal migration in P19 embryonal carcinoma stem cell aggregates. J Neurosci Res 2005; 81: 9-20.

34. Surveyor GA, Brigstock DR. Immunohistochemical localization of connective tissue growth factor (CTGF) in the mouse embryo between days 7.5 and 14.5 of gestation. Growth Factors 1999; 17: 115-124.

35. Ponticos M, Holmes AM, Shi-wen X, Leoni P, Khan K, Rajkumar VS, et al. Pivotal role of connective tissue growth factor in lung fibrosis: MAPK-dependent transcriptional activation of type I collagen. Arthritis Rheum 2009; 60: 2142-2155.

36. Kang Y, Siegel PM, Shu W, Drobnjak M, Kakonen SM, Cordon-Cardo $\mathrm{C}$, et al. A multigenic program mediating breast cancer metastasis to bone. Cancer Cell 2003; 3: 537-549.

37. Aikawa T, Gunn J, Spong SM, Klaus SJ, Korc M. Connective tissue growth factor-specific antibody attenuates tumor growth, metastasis, and angiogenesis in an orthotopic mouse model of pancreatic cancer. Mol Cancer Ther 2006; 5: 1108-1116.

38. Pi L, Ding X, Jorgensen M, Pan JJ, Oh SH, Pintilie D, et al. Connective tissue growth factor with a novel fibronectin binding site promotes cell adhesion and migration during rat oval cell activation. Hepatology 2008; 47: 996-1004.

39. Chaqour B, Goppelt-Struebe M. Mechanical regulation of the Cyr61/CCN1 and CTGF/CCN2 proteins. FEBS J 2006; 273: 3639-3649.

40. Jasmin, Spray DC, Campos de Carvalho AC, Mendez-Otero $\mathrm{R}$. Chemical induction of cardiac differentiation in p19 embryonal carcinoma stem cells. Stem Cells Dev 2010; 19: 403-412. 